\title{
What is more effective: a daily or a weekly formative test?
}

\author{
Leonieke N. Palmen • Marc A.T.M. Vorstenbosch • \\ Esther Tanck $\cdot$ Jan G.M. Kooloos
}

Published online: 31 March 2015

(C) The Author(s) 2015. This article is published with open access at Springerlink.com

\begin{abstract}
Background Exams in anatomy courses are traditionally summative. Formative testing induces retrieval practice, provides feedback and enhances learning results. We investigated the optimal frequency for retrieval practice during an anatomy course.

Method During a first-year course, students were offered four online daily quizzes a week that assessed thoracic anatomy. Once a week they received a quiz about abdominal anatomy. Students immediately received feedback afterwards. In the fourth course week, a survey about participation and satisfaction was taken. 424 students participated in the final summative exam. Trunk wall questions were used as a control. Relationship between participation and test results was investigated with a one-way ANOVA.

Results More frequent participation in formative tests was correlated to higher scores in the summative exam with no difference between daily and weekly quizzes. This effect was found for thorax-abdomen and 'control' trunk wall questions. Participation in weekly quizzes was higher $(p<0.001)$. All survey responses showed a significant difference in favour of the weekly quiz $(p<0.001)$.

Discussion and conclusion Participation in formative quizzes was correlated to summative exam scores. This correlation was not specific for the material tested, probably
\end{abstract}

L. N. Palmen $(\bowtie) \cdot$ M. A. Vorstenbosch · J. G. Kooloos

Department of Anatomy,

Radboud University Medical Centre Nijmegen,

PO Box 9101, 6500 Nijmegen, the Netherlands

e-mail: ln.palmen@gmail.com

E. Tanck

Orthopaedic Research Laboratory,

Radboud University Medical Centre,

Nijmegen, the Netherlands because of diligence. Student participation and preference were much higher in weekly quizzes.

Keywords Formative test $\cdot$ Student participation · Student satisfaction

\section{Introduction}

Anatomy has always been one of the basic sciences of medical school. Anatomical knowledge is traditionally tested by means of summative examination, providing information for pass/fail decisions. Karpicke and Roediger showed that repeated testing produced a large positive effect on long-term retention, while repeated studying had no effect [1]. This is called the 'testing effect' $[2,3]$. In spaced education this testing effect or retrieval practice is combined with the 'spacing effect' [4]. If information is repeated over spaced intervals of time, the retention is better than if information is offered all at once. Kerfoot demonstrated that spaced education also improved retention of medical knowledge [5]. The goal of formative testing is to enhance learning, whereas summative testing is aimed at grading or decision making. Formative testing can also enhance learning through other ways, for instance through improving motivation and study strategy. Following frequent testing, most students increase their study time and change their strategies [4]. Frequent testing also encourages students to space their study efforts [2].

Rolfe [6] proposed that a formative assessment should be voluntary in nature, non-judgmental, available with rapid feedback, and designed with opportunities to remediate deficiencies. Formative assessments should be offered to the students during the learning period [6].According to Chan et al. [7] retrieval practice could also increase retention of related information, i.e. information that was not part 
of the test itself.Providing feedback after a retrieval attempt supports future successful retrieval [8].

There are indications that formative assessment during a course improves the student's performance on the final summative exam [9]. Kibble found that students who took formative online quizzes during the course showed better outcomes on summative exams compared with students who chose not to take quizzes. He also showed that offering course credits for taking formative tests increased student participation [10]. Logan et al. [11] described an experiment during a first-year anatomy course in which students could voluntarily take course-content-related quizzes. Although the students were not enthusiastic about the quizzes, a significant improvement on the final exam was found in the scores of those students who actually took the quizzes.

According to Roediger, repeated retrievals outperform single retrievals [2].It is suggested that the best retrieval schedules involve wide spacing of retrieval attempts [12]. Two strategies of retrieval schedules are described. In an equally spaced schedule, retrievals are evenly spaced with the same amount of time between each retrieval [13]. In an expanding schedule, which was first proposed by Landauer and Bjork [14], each retrieval attempt occurs after an increasingly longer interval. Some studies showed no differences in learning effect between these two retrieval schedules (Balota [15] and Logan [16]), while yet another study (Karpicke [17]) concluded that equally spaced practice led to better long-term retention. Karpicke also pointed out that feedback enriched retention in both the expanding and equally spaced conditions. Nevertheless, the general opinion on what is supposed to be the best retrieval schedule to offer formative assessments to students remains unclear.

The aim of the present study was to further investigate the optimal frequency for retrieval practice through formative assessments in educational practice. The research question was: What is the difference between daily and weekly quizzes, offered during an anatomy course, in terms of learning gain, student participation, and student satisfaction?

\section{Methods}

\section{Ethical considerations}

During the introductory lecture on the first day of the course, the students were informed about the procedures and the purpose of the experiment with the daily and weekly quizzes. Later, the students also received this information by email. It was explained to the students that participation in the experiment was voluntary and that students who did not participate still had access to the quizzes. Because of this, participation would not introduce inequality between students. Moreover, the within-subject design guaranteed that no inequality was introduced amongst participants. After merging data from quiz records and assessment results, data were anonymized for analysis and storage. Results presented in this paper cannot be traced back to individual participants. At the end of the course, the participants were asked to give their written consent to use of their records for this study.

\section{Educational setting}

Radboud university medical center, the Netherlands, offers a six-year medical educational programme. In a first-year course, the students are introduced to the gross anatomy of the thorax, abdomen, and pelvis. It is a four-week, $160 \mathrm{~h}$ course in which the organs and walls of the thorax, abdomen, and pelvis are covered. Instructional methods used are lectures, self-study assignments, interactive lectures, computer-assisted learning, collaborative learning, laboratory sessions with prosected specimens, and body painting. The students are assessed in a final summative exam at the end of the fourth week.

\section{The formative tests}

Two sets of formative exams were completed by three anatomy teachers. The questions were designed to resemble the content, format and difficulty of the final exam at the end of the course.

During the first three weeks of the course, short daily quizzes about thoracic anatomy were offered to the students on Monday through Thursday. Every quiz had two or three short questions. On Friday a weekly quiz about the abdominal anatomy was offered, containing about ten questions. The daily quizzes and weekly quizzes both consisted of extended matching questions (Fig. 1). The number of questions was similar for daily and weekly quizzes. After a quiz had been completed, immediate feedback was given

Answer options:

Given the structures below, located in the abdomen

$\begin{array}{llll}\text { A } & \text { Hepatic duct } & \text { H } & \text { Left renal vein } \\ \text { B } & \text { Bile duct } & \text { I } & \text { Left hepatic artery } \\ \text { C } & \text { Portal vein } & \text { J } & \text { Left gastric artery } \\ \text { D } & \text { Superior mesenteric vein } & \text { K } & \text { Splenic artery } \\ \text { E } & \text { Inferior mesenteric vein } & \text { L } & \text { Left renal artery } \\ \text { F } & \text { Splenic vein } & \text { M } & \text { Right renal artery } \\ \text { G } & \text { Left hepatic vein } & \text { N } & \text { Abdominal aorta }\end{array}$

Instruction

Which of the structures above meet the definitions below? Put the corresponding letters in the space behind the definition. The number written in brackets indicates the maximum number of answers allowed

\begin{tabular}{|l|l|l|l|l|l|l|}
\hline 1 & $\begin{array}{l}\text { Which structures are located in the } \\
\text { retroperitoneum? }\end{array}$ & (4) & H & L & M & N \\
\hline 2 & Which structure joins the pancreatic duct? & (1) & B & & & \\
\hline 2 & $\begin{array}{l}\text { Which structures lie dorsal from the } \\
\text { pancreas? }\end{array}$ & (2) & D & N & & \\
\hline
\end{tabular}

Fig. 1 Example of questions in a formative test 
by showing the right answers. Both forms of formative testing were presented online via Blackboard, the institution's online education platform. The students were alerted by email when a quiz became available. While a quiz was online, the students could take it as many times as they liked. Availability was limited to discourage saving all the quizzes until later in the course. Each daily quiz was available for $24 \mathrm{~h}$ and each weekly quiz for 3.5 days. Participation was registered in Blackboard. Participants received no extra study credits.

The survey and summative examination

During the fourth week of the course, students were asked to complete a written survey about both forms of formative testing, focusing on their participation and satisfaction. Before we conducted the survey, we optimized its questions with anatomy colleagues. We did not conduct a pilot survey on students.

Three anatomy teachers divided the questions of the summative exam into three categories: thoracic anatomy, abdominal anatomy, and the trunk wall. This last category served as control, because the students did not take quizzes on this subject during the course. If there were doubts about the category a question best fitted in, then that question was excluded. Embryological questions were also excluded.

\section{Adapted Angoff procedure}

To compare the scores in the three categories, we needed an indication of the difficulty of the questions used in the summative exam. We therefore used an adapted Angoff procedure [18]. Five senior medical students who assisted teaching during the course estimated the difficulty of every question in the summative exam on a six-point Likert scale ( $1=$ very simple; $6=$ very difficult). These difficulty ratings were averaged across the raters for every question and then multiplied with the student scores on the question to obtain a score that was corrected for difficulty. These five students were blinded for the purpose of this procedure.

Outcome measures and data analysis

Students were included in this study if they participated in the summative exam and gave written consent to this investigation by completing the survey. The total score on the summative exam was registered and divided into scores on thoracic anatomy, abdominal anatomy, and body wall anatomy. These scores were mathematically corrected for difficulty by using the results of the adapted Angoff procedure.

Participation in daily quizzes was divided into quartiles: 0-3 quizzes completed [0], 4-6 quizzes completed [1], 7-9 quizzes completed [2], 10-12 quizzes completed [3]. Partic-
Table 1 Student survey

\begin{tabular}{|c|c|c|c|}
\hline Question & & Mean & Paired sample t-test \\
\hline $\begin{array}{l}\text { I always participated } \\
\text { in the quizzes }\end{array}$ & $\begin{array}{l}\text { Daily quiz } \\
\text { Weekly quiz }\end{array}$ & $\begin{array}{l}3.56 \\
2.67\end{array}$ & $\begin{array}{l}\mathrm{t}=13.52 \\
\mathrm{df}=423 \\
p=0.000\end{array}$ \\
\hline $\begin{array}{l}\text { I perceived doing the } \\
\text { quizzes as useful }\end{array}$ & $\begin{array}{l}\text { Daily quiz } \\
\text { Weekly quiz }\end{array}$ & $\begin{array}{l}2.42 \\
1.99\end{array}$ & $\begin{array}{l}\mathrm{t}=7.55 \\
\mathrm{df}=410 \\
p=0.000\end{array}$ \\
\hline $\begin{array}{l}\text { The quizzes were } \\
\text { available long enough }\end{array}$ & $\begin{array}{l}\text { Daily quiz } \\
\text { Weekly quiz }\end{array}$ & $\begin{array}{l}3.70 \\
2.57\end{array}$ & $\begin{array}{l}\mathrm{t}=13.95 \\
\mathrm{df}=416 \\
p=0.000\end{array}$ \\
\hline $\begin{array}{l}\text { aHow many times did } \\
\text { I take the quizzes? }\end{array}$ & $\begin{array}{l}\text { Daily quiz } \\
\text { Weekly quiz }\end{array}$ & $\begin{array}{l}1.186 \\
1.25\end{array}$ & $\begin{array}{l}\mathrm{t}=-1.94 \\
\mathrm{df}=418 \\
p=0.053\end{array}$ \\
\hline $\begin{array}{l}\text { The quizzes enhanced } \\
\text { my study efforts }\end{array}$ & $\begin{array}{l}\text { Daily quiz } \\
\text { Weekly quiz }\end{array}$ & $\begin{array}{l}4.10 \\
3.71\end{array}$ & $\begin{array}{l}\mathrm{t}=7.77 \\
\mathrm{df}=416 \\
p=0.000\end{array}$ \\
\hline $\begin{array}{l}\text { Other courses should } \\
\text { offer comparable } \\
\text { quizzes }\end{array}$ & $\begin{array}{l}\text { Daily quiz } \\
\text { Weekly quiz }\end{array}$ & $\begin{array}{l}2.20 \\
1.84\end{array}$ & $\begin{array}{l}\mathrm{t}=7.55 \\
\mathrm{df}=418 \\
p=0.000\end{array}$ \\
\hline $\begin{array}{l}\text { I would take quizzes } \\
\text { like this in other } \\
\text { courses }\end{array}$ & $\begin{array}{l}\text { Daily quiz } \\
\text { Weekly quiz }\end{array}$ & $\begin{array}{l}2.31 \\
1.94\end{array}$ & $\begin{array}{l}\mathrm{T}=8.40 \\
\mathrm{Df}=418 \\
p=.000\end{array}$ \\
\hline
\end{tabular}

The questions were answered using a six-point Likert scale ( $1=$ totally agree, $6=$ totally disagree)

${ }^{a}$ The students filled in how many times they completed the quizzes ( $1=1$ time, $5=5+$ times $)$

ipation in weekly quizzes was divided in quartiles as well: 0 quizzes completed [0], 1 quiz completed [1], 2 quizzes completed [2], 3 quizzes completed [3].

The relationship between participation in both forms of formative testing and the scores of the students in the summative exam were analyzed with a one-way ANOVA.

The students' opinions about the quizzes were enquired about in a survey (Table 1). This survey was analyzed by means of a paired samples t-test.

\section{Results}

Student participation rates

\section{Daily quizzes}

A total of twelve daily quizzes were offered to the students during the course period. Quiz participation ranged from 0 to 12 quizzes. Participation in daily quizzes was as follows: $39.2 \%$ completed $0-3$ quizzes, $18.6 \%$ 4-6 quizzes, $7-9$ quizzes were completed by $20 \%$ of the students and $22.2 \%$ completed 10-12 quizzes. Closer to the summative exam, a significantly higher participation was found. During the first week the average participation rate was 1.58 quizzes versus 2.06 quizzes in the third week (repeated measures ANOVA $F=34.4 ; p<0.001)$. 


\section{Weekly quizzes}

Regarding the weekly quizzes, participation ranged from 0 to 3 quizzes. Sixty-three students $(14.9 \%)$ did not complete any of the quizzes. A total of $12.3 \%$ of the students completed one weekly quiz, while $22.9 \%$ completed two quizzes. Half of the students $(50 \%)$ completed all three weekly quizzes. Participation rate in the third week of the course period was significantly higher than participation rate in the first week. The average participation rate during the first week was 0.65 versus 0.76 during the third week (repeated measures ANOVA $F=19.7 ; p<0.001$ ). This rate is below 1.0 because only one weekly quiz per week was offered to the students.

\section{Effect of quiz participation on the summative exam}

Positive relationships were found between the number of quizzes that the students completed (participation rate) and their scores in the final summative exam. This relationship did not change when the scores in the summative exam were corrected for difficulty and was observed for both the daily (Table 2) and the weekly quizzes (Table 3). Scores for questions about the thorax and abdomen as well as scores for questions about the trunk wall (Table 2 and 3) significantly increased with participation rate in both forms of formative quizzes. This shows there was no difference between daily and weekly quizzes with respect to their effect on learning.

\section{Student survey}

A total of 424 students consented to participate in the experiment and filled in the survey about their quiz experience (Table 1). All questions showed a significant difference in favour of the weekly quizzes $(p<0.001)$, except the question about how many times they did each quiz $(p=0.053)$. Students were honest in the survey about their participation: reported participation and registered participation were pretty similar. The students indicated that both the daily and the weekly quizzes did not enhance their study efforts.

Table 2 Cross-tabulation of participation rate in the daily quizzes versus total and partial summative test scores presented as a percentage of maximal score and corrected for difficulty

\begin{tabular}{lllll}
\hline $\begin{array}{l}\text { Participa- } \\
\text { tion rate }\end{array}$ & $\begin{array}{l}\text { Total score sum- } \\
\text { mative test }(\%)\end{array}$ & $\begin{array}{l}\text { Score } \\
\text { thorax }(\%)\end{array}$ & $\begin{array}{l}\text { Score abdo- } \\
\text { men }(\%)\end{array}$ & $\begin{array}{l}\text { Score trunk } \\
\text { wall }(\%)\end{array}$ \\
\hline $0-3$ & 70.8 & 74.2 & 70.0 & 69.3 \\
$4-6$ & 73.9 & 76.8 & 74.0 & 72.1 \\
$7-9$ & 76.3 & 79.3 & 75.3 & 75.2 \\
$10-12$ & 82.6 & 83.1 & 77.0 & 79.1 \\
One-way & $\mathrm{df}=3 / 423$ & $\mathrm{df}=3 / 423$ & $\mathrm{df}=3 / 423$ & $\mathrm{df}=3 / 423$ \\
ANOVA & $\mathrm{F}=24.06$ & $\mathrm{~F}=15.65$ & $\mathrm{~F}=12,27$ & $\mathrm{~F}=17.22$ \\
& $p=0.000$ & $p=0.000$ & $p=0.000$ & $p=0.000$ \\
\hline
\end{tabular}

Table 3 Cross-tabulation of participation rate in the weekly quizzes versus total and partial summative test scores, presented as a percentage of maximal score and corrected for difficulty

\begin{tabular}{lllll}
\hline $\begin{array}{l}\text { Participa- } \\
\text { tion rate }\end{array}$ & $\begin{array}{l}\text { Total score sum- } \\
\text { mative test }(\%)\end{array}$ & $\begin{array}{l}\text { Score } \\
\text { thorax }(\%)\end{array}$ & $\begin{array}{l}\text { Score abdo- } \\
\text { men }(\%)\end{array}$ & $\begin{array}{l}\text { Score trunk } \\
\text { wall }(\%)\end{array}$ \\
\hline 0 & 69.1 & 72.3 & 68.2 & 67.9 \\
1 & 70.8 & 74.4 & 70.7 & 68.7 \\
2 & 73.5 & 77.1 & 72.6 & 72.0 \\
3 & 77.3 & 80.3 & 75.9 & 76.4 \\
One-way & $\mathrm{df}=3 / 423$ & $\mathrm{df}=3 / 423$ & $\mathrm{df}=3 / 423$ & $\mathrm{df}=3 / 423$ \\
ANOVA & $\mathrm{F}=20.55$ & $\mathrm{~F}=11.81$ & $\mathrm{~F}=12.65$ & $\mathrm{~F}=14.32$ \\
& $p=0.000$ & $p=0.000$ & $p=0.000$ & $p=0.000$ \\
\hline
\end{tabular}

The weekly quizzes were strongly preferred by $42.5 \%$ of the students versus $12.3 \%$ of the students who preferred the daily quizzes. They also stated they had learned more from the weekly quizzes ( 48 vs. $6.8 \%$ ). If they had to choose between the two forms of formative testing, $60.5 \%$ of the students had a strong preference for the weekly quiz. The daily quiz was preferred by $11.1 \%$ of the students.

\section{Discussion}

Comparing daily and weekly quizzes we found no effect on learning gain. However, a higher student participation for weekly quizzes was found as was a higher preference for these.

Learning gain

The results of this study showed that more frequent participation in both forms of formative tests is correlated to higher scores on all three discerned parts of the summative exam and this suggests a causal relationship. Results did not show a difference between the anatomical categories that were enquired about in daily quizzes on one hand and in weekly quizzes on the other. Moreover, even the scores in the control category (trunk wall) increased with the participation in both daily quizzes and weekly quizzes. These findings indicate that no difference exists between the influence of the daily and weekly quizzes on learning.

Diligence may be an important confounder. Diligence may be described as the effort expended by students to achieve [19]. Honea found a statistically significant relationship between student diligence and academic achievement [20]. More diligent students are more likely to participate in formative testing and also more likely to perform better on the summative examination. Students who exploit all learning possibilities, including quizzes like in this study, have a higher chance of successful outcomes [21]. To obtain an indication of the diligence of the individual student and to correct for this diligence in future research, 
we could possibly correlate test results of other courses to our test results. We could also use one of the reliable and valid instruments developed to measure student's diligence, for example the Diligence Inventory-Higher Education (DIHE), designed by Bernard and Schuttenberg [22].

We did not determine the influence of gender on our results, but gender might also be a confounder. Previous research has shown that women perform better than men $[23,24]$, but recent findings by Masui et al. [25] show that gender only occasionally plays a role in achievement. On the other hand, Masui et al. show in the same study that feminine gender positively influences study time and that more study time predicts better grades.

Furthermore, all other learning activities in our educational setting (lectures, self-study assignments, interactive lectures and so on) might have subdued the testing effect that was found previously by Roediger in a non-educational setting [2]. Our study did not register how students studied the course content.

\section{Student participation}

Participation rate in the weekly quizzes was much higher compared with the participation rate in the daily quizzes. Comments from the survey showed that students were annoyed by the fact they received a daily quiz accompanied by an email every day. Contrary to the scattered contents of the daily quiz, weekly quizzes provided some kind of overview of the work done that week. Moreover, the weekly quiz was available longer online than the daily quiz and also available during the weekend. Participation in the third week of the course was higher than in the first week, probably because of the upcoming exam.

\section{Student satisfaction}

The results of the survey showed that students perceived both the daily and weekly quizzes as useful. This is probably because of the voluntary basis and the immediate feedback after completing the quizzes. Student reactions in other studies confirm this $[12,26]$.

In the student survey, 88 students $(20.8 \%)$ stated that the quizzes should be online for a longer period of time. It is understandable that quizzes available at any time would be more popular than quizzes, only available for $24 \mathrm{~h}$, like the daily quizzes. However, to obtain objective data during this study, it was necessary to give the quizzes under controlled conditions. A small number of 15 students $(3.5 \%)$ felt the questions about the thoracic anatomy were too easy; they had expected growing difficulty of these questions during the course.

\section{Conclusion}

Participation of students in formative quizzes in an anatomy course is correlated to the scores on the final summative exam. We found no difference in effect on test results between daily and weekly quizzes. Based on the higher student participation and student satisfaction we propose weekly quizzes as a more successful retrieval schedule than daily quizzes.

\section{Essentials}

- Formative testing induces retrieval practice, provides feedback and enhances learning results.

- In this study, we investigated the optimal frequency for retrieval practice during an anatomy course by offering both daily and weekly quizzes to the students.

- The effect of daily and weekly quizzes on test results, student participation and student satisfaction was studied.

- Participation of students in formative quizzes in an anatomy course is correlated to test scores, but it is not specific for the test material, probably because of diligence.

- Student participation and preference are much higher for weekly quizzes.

Open Access This article is distributed under the terms of the Creative Commons Attribution License which permits any use, distribution, and reproduction in any medium, provided the original author(s) and source are credited.

\section{References}

1. Karpicke JD, Roediger HL. The critical importance of retrieval for learning. Science. 2008;319:966-8.

2. Roediger HL, Karpicke JD. Test-enhanced learning: taking memory tests improves long-term retention. Psychol Sci. 2006;17:249-55.

3. Karpicke JD, Roediger HL. Repeated retrieval during learning is the key to long-term retention. J Mem Lang. 2007;57:151-62.

4. Larsen DP, Butler AC, Roediger HL. Test-enhanced learning in medical education. Med Educ. 2008;42:959-66.

5. Kerfoot BP, DeWolf WC, Masser BA, Church PA, Federman DD. Spaced education improves the retention of clinical knowledge by medical students: a randomized controlled trial. Med Educ. 2007;41:23-31.

6. Rolfe I, McPherson J. Formative assessment: how am I doing? Lancet. 1995; 345:837-39.

7. Chan JCK. Long-term effects of testing on the recall of nontested materials. Memory. 2010;18:49-57.

8. Butler AC, Karpicke JD, Roediger HL. Correcting a metacognitive error: feedback enhances retention of low confidence correct responses. J Exp Psychol Learn Mem Cogn. 2008;34: 918-28.

9. Tanck E, Hannink G, van Kuppeveld SM, Bolhuis S, Kooloos JG. The use of daily questions for educational purposes: a TOPday for students. Perspect Med Educ. 2013;2:162-4. 
10. Kibble J. Use of unsupervised online quizzes as formative assessment in a medical physiology course: effects of incentives on student participation and performance. Adv Physiol Educ. 2007;31:253-60.

11. Logan JM, Thompson AJ, Marshak DW. Testing to enhance retention in human anatomy. Anat Sci Educ. 2011;4:243-8.

12. Pyc MA, Rawson KA. Testing the retrieval effort hypothesis: does greater difficulty correctly recalling information lead to higher levels of memory. J Mem Lang. 2009;60:437-47.

13. Crowder, R. The effects of repetition. In: Principles of learning and Memory, pp. 264-321. Hillsdale: Lawrence Erlbaum Associates; 1976.

14. Landauer, TK, Bjork, RA. Optimum rehearsal patterns and name learning. In: Practical Aspects of Memory, pp. 625-32. London: Academic Press; 1987.

15. Balota DA, Duchek JM, Sergent-Marshall SD, Roediger HL. Does expanded retrieval produce benefits over equal interval spacing? Explorations of spacing effects in healthy aging and early stage Alzheimer's disease. Psych Aging. 2006;21:19-31.

16. Logan JM, Balota DA. Expanded vs. equal interval spaced retrieval practice: exploration of schedule of spacing and retention interval in younger and older adults. Aging Neuropsychol Cogn. 2008;15(3):257-80.

17. Karpicke JD, Roediger HL. Expanding retrieval practice promotes short-term retention, but equally spaced retrieval enhances longterm retention. J Exp Psychol Learn Mem Cogn. 2007;33:704-19.

18. Kane MT, Crooks TJ, Cohen AS. Designing and evaluating standard-setting procedures for licensure and certification tests. Adv Health Sci Educ. 1999;4:195-207.

19. Bernard H, Thayer JD, Streeter EA. Diligence and academic performance. J Res Christ Educ. 1993;2:213-34.

20. The effect of student diligence, diligence support systems, selfefficacy, and locus of control on academic achievement. Unpublished doctoral dissertation. Tennessee State University, 2007.

21. Heffler B. Individual learning style and the learning style inventory. Educ Stud. 2001;27:307-16.

22. Bernard H, Schuttenberg EM. Development of the diligence inventory-higher education form. J Res Dev Educ. 1995;28:91-100.
23. Barrow M, Reilly B, Woodfield R. The determinants of undergraduate degree performance: how important is gender? Br Educ Res J. 2009;35:575-97.

24. Bruinsma M, Jansen EPWA. When will I succeed in my first-year diploma? Survival analysis in Dutch higher education. High Educ Res Dev. 2009;28:99-114.

25. Masui C, Broeckmans J, Doumen S, Groenen A, Molenberghs G. Do diligent students perform better? Complex relations between student and course characteristics, study time, and academic performance in higher education. Stud High Educ. 2014;39:621-43.

26. Evans DJR, Zeun P, Stanier RA. Motivating student learning using a formative assessment. J Anat. 2014;224:296-303.

Leonieke N. Palmen is a medical doctor. At the time of this research, she worked at the Department of Anatomy at Radboud University Nijmegen Medical Centre, the Netherlands. She taught gross anatomy and functional anatomy of the locomotor system. Leonieke has a special interest in orthopaedic surgery.

Marc A.T.M. Vorstenbosch is an senior lecturer in the Department of Anatomy at Radboud University Nijmegen Medical Centre, the Netherlands. He teaches gross anatomy, embryology, histology and functional anatomy of the locomotor system and is involved in several research projects involving anatomy education.

Esther Tanck is an assistant professor and senior lecturer at the Department of Orthopaedics at the Radboud University Nijmegen Medical Centre, Nijmegen, the Netherlands. She is major tutor of Clinical Human Movement Sciences and supervises PhD students who work on biomechanical issues.

Jan G.M. Kooloos is an associate professor and senior lecturer in the Department of Anatomy at Radboud University Nijmegen Medical Centre, Nijmegen, the Netherlands. He teaches gross anatomy, embryology, histology and functional anatomy of the locomotor system and is involved in several research projects involving anatomy education. 